\title{
THE ADRENO-GENITAL SYNDROME
}

By S. Leonard Simpson, M.A., M.D., F.R.C.P. Consultant Endocrinologist, St. Mary's Hospital, and Endocrinologist to the Paediatric Unit

The potential influence of the adrenal gland over sexual development, particularly in regard to pseudohermaphroditism and pseudosexual precocity, has of course been known for very many years, with the paper of Bulloch and Sequeira (1905) constituting a landmark in the elucidation of our clinico-pathological knowledge. The term 'adreno-genital syndrome' or 'le syndrome génito-surrénal' was introduced in France by Gallais in 1912, and in modern endocrinological literature this term is limited to those cases which first manifest themselves in adult life. Gardiner Hill and Broster (1932) separated from this group a puberty type in which the initial manifestation dated from puberty and this is a useful classification from some angles, although a comprehensive study of the adreno-genital group will show that many patients with symptoms manifesting themselves in the late teens or in the third decade have had minor manifestations at puberty and, further, a study of paediatric endocrinology frequently shows prognostic indications in early childhood. This is not unexpected as there is no doubt that nearly all the cases, other than those caused by adrenal or ovarian neoplasms, are genetic in origin, and in fact the writer has put forward a number of considerations in favour of the view that a proportion of the adrenal neoplasms themselves may be genetic in origin and may be preceded by hyperplasia. However, since by definition, amenorrhoea or oligomenorrhoea is an essential feature of the adreno-genital syndrome, it could not be diagnosed before puberty, and it is proposed in this article to limit the main considerations to the adult group which includes those starting at puberty.

A second feature of the syndrome is hirsutism, meaning hairiness of so-called male distribution such as hair on the upper lip, on the chin, sides of the face and of the abdomen spreading from the pubes in triangular fashion to the umbilicus. This leads us into considerable difficulties, if exactitude is required, because an appreciable percentage of 3 . normal women in all countries, and particularly in Latin countries, have such a distribution of hair; nor is it possible to make any clear-cut division as to the intensity of hair growth apart from the distribution. The intensity of such hair growth in normal women, although normal and genetic and although influenced by the distribution of hair follicles, may well be determined by a greater intensity than average adrenal androgenic stimulus, as is indicated by its onset or augmentation ab $\vec{\oplus}$ puberty, pregnancy, or the climacteric. In othe fs women, more intense hair growth appears in the third decade, or before, without an obvious endocrine stimulus, although closer study may indicate other manifestations of increased adrenal cortex activity. Amenorrhoea may be absolute, but when it is scanty at monthly, or longer or irregular intervals, we are again faced with the difficulty of clear-cut division from accepted normality and can best solve this dilemma by accepting that there is no such clear-cut division.

The third triad of this syndrome is usually put forward as adiposity, but in actual fact there are two groups: the adipose and the muscular, in which latter not only may there be no increase in the deposition of adipose tissue but the normal adipose tissue may diminish or disappear. As 0 regards the adipose group, Cushing has separated 을 from these a more complex and flamboyant syn- $\frac{T}{0}$ drome which is known by his name and which is dealt with separately in this Journal. However, of we must recognize that of the additional features $N$ such as hypertension, diabetes, osteoporosis, poly- N cythemia, plethora, acrocyanosis, some pigmenta- $\sigma$ tion and hypopotassaemic alkalosis, not all of these are necessarily present for the diagnosis of $\stackrel{\bullet}{C}$

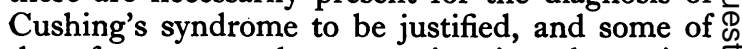
these features may be present in minor degree in a good proportion of cases in which the diagnosis of 0 adreno-genital syndrome is more appropriate $\underset{\mathbb{D}}{\mathrm{P}}$ and would not be queried. Thus, such patients $\frac{\rho}{\mathbb{Q}}$ 


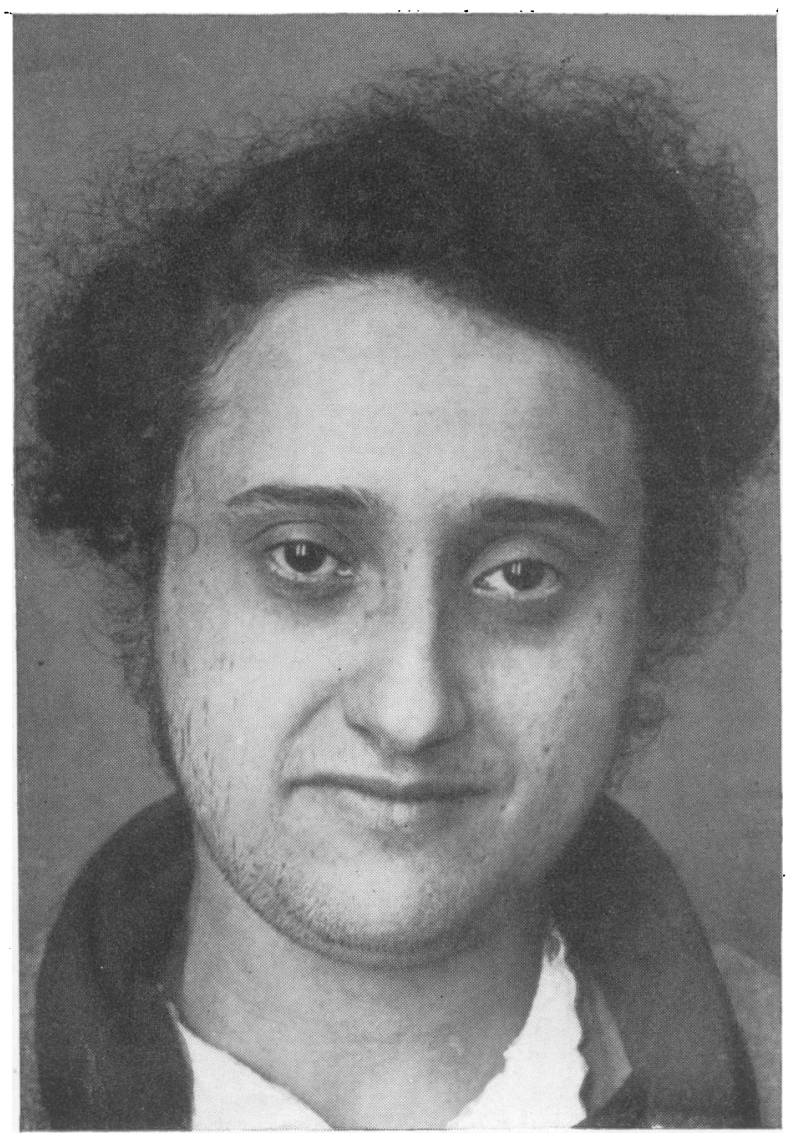

FIG. I.-Adreno-genital syndrome in woman of twenty-eight. The first patient in whom an excess of urinary androgenic prostate stimulating and comb growth hormone was demonstrated. Note orbital pigmentation. (Simpson, 1934; Simpson, et al., 1936.) (By permission of Oxford University Press.)

often have a good colour and even mild plethora, some pigmentation, e.g. of orbits, may be present, the blood pressure may well be moderately raised and very frequently the carbohydrate tolerance curve shows a retarded rate of fall so that the blood sugar remains appreciably above normal for two or more hours after the taking of the glucose. Further, a high percentage show urinary glucocorticoids slightly above normal (Robinson and Norton, 195 I). The majority of cases of adrenogenital syndrome, however, do not pass into the state of Cushing's syndrome, at least within a decade, but followed over a lifetime the final picture may be indistinguishable from the more chronic forms of Cushing's syndrome (Simpson, I95Ia).

The muscular type of adreno-genital syndrome is well illustrated by Gordon Holmes's classical case of 1924: a beautiful girl of 17 , with normal feminine contours, ceases to menstruate and at 19 develops hair on face and body. By 24 , she has lost all her subcutaneous fat and associated feminine contours and has become muscular, masculine and strong. An adrenal tumour is found and removed. The patient regains her normal subcutaneous fat, her normal feminine contours, her normal menstruation and at the same time loses all the abnormal hair. The author was able to record that she remained normally well when last seen at the age of 35 . Here we have an example of an adrenal hyperfunction (androgenic) causing a loss of trunk fat in contrast with adrenal glucocorticosteroid hyperfunction with deposition of face and trunk fat. Another feature of this type is enlargement of the clitoris which may be considerable. This is rarely met with in the adipose type. Other manifestations of the adrenal androgenic stimulus are thickening of the eyebrows, with 
a tendency for hair to grow between them, and loss of scalp hair with retraction from the temporofrontal areas giving increased height to the forehead, characteristic of the male and interpreted by him in his own case as a manifestation of greater intellect. A greasy skin, acne and seborrhoea are other features. Some of the muscular types show a poor development or even involution of the breasts, and the width of the pelvis may be less than or no greater than that of the shoulders, as in the male in contrast to the wider pelvis of the normal female. These patients are often strong and may well achieve athletic prowess by virtue of their adrenal androgenic constitution.

Any clinician with wide experience will realise that there are many intermediate types between the adipose and the muscular groups of adrenogenital syndrome. We may venture to speak in hormone terminology of three types: (I) predominantly androgenic, (2) mixed androgenicglucocorticoid, and (3) predominantly corticosteroid, although this brings (3) into an imperceptible gradation to Cushing's syndrome. This classification may well be modified by further hormone study and is not fully substantiated by investigations up to date.

We have already mentioned that Cushing has separated one group from the adipose type. I think it is justifiable to say that, at least from a clinical angle, my observations on children and their relatives, and the subsequent follow-up of these cases, may have indicated another subgroup. I refer to the syndrome which I have described under the name of adipose gynism. This may manifest itself in childhood, frequently at the age of 7 , or at puberty. It may then be progressive or may ameliorate to accepted normality and recur in the second or third decade, sometimes precipitated by pregnancy. The condition has been described fully in a previous edition of this Journal (Simpson, 1950) and also subsequently (Simpson, I95 Ia). Its main features are adiposity, tallness but early union of the epiphyses, premature menstruation, plethora, acrocyanosis, large breasts with broad areolae, red lineae distensae and mild hirsutism in some cases. Menstruation may be regular and of normal amount, but oligomenorrhoea may be a feature in some patients in adult life. In such cases the differentiation from the adipose type of adreno-genital syndrome may be difficult or impossible. At any rate it is a subject that calls for further study and that cannot be omitted from our considerations.

\section{Pathology}

The pathology of the adreno-genital syndrome is adrenal hyperplasia and hyperfunction, although

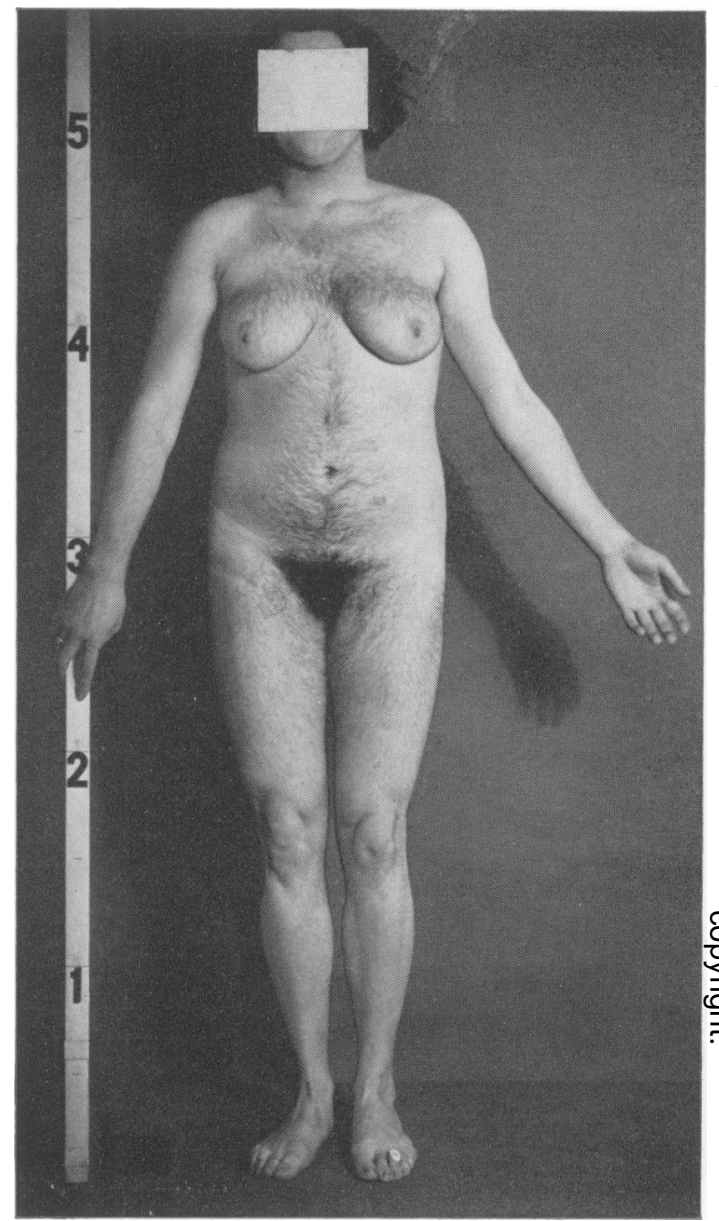

FIG. 2.-Virilism in big-boned woman with prognathism, aged twenty-one at time of photograph. Menstruation was normal from age fourteen to sixteen when amenorrhoea developed, together with hirsutism, deepening of voice and increase of weight. Radiography after uroselectan showed a right adrenal tumour, which was removed (age twenty-one), after which menstruation became regular once more but hirsutism persisted. The I 7-ketosteroids were very high (143 mg. per day) before operation, and although reduced by more than 50 per cent., still remain very high, namely $55 \mathrm{mg}$. per day as compared with the normal of 5 to $12 \mathrm{mg}$. This explains the persistent hirsutism I5 years after operation. Abdominal laparotomy I I years after operation did not reveal any neoplasm in the pelvis or adrenal areas. The left adrenal was moderately enlarged. Hirsutism 15 years after operation remains the same. A primary and persistent pituitary stimulus is postulated. Milder examples of pituitary big-bone types of adrenogenital syndrome without neoplasm are not uncommon. (Photograph by permission of Oxford University Press.) 
such hyperplasia may not be indicated by any increase in weight of the glands above the normal range or by ordinary histological methods. Broster et al. (1938) have attached considerable importance to the staining of such glands with ponceau-fuchsin dye and there is little doubt that a high proportion of such glands take up this stain strongly, e.g. in one series they obtained it in 34 out of 36 , though the degree and distribution of fuchsinophil cells varied appreciably and was not correlated with the clinical condition. Nevertheless they feel justified in correlating the fuchsinophil staining with the androgen-secreting properties of adrenocortical cells, and they also found similar fuchsinophil cells in the male foetus from the age of 9 to 20 weeks; in the female, such cells were only present from the I I th to the I4th week and did not stain with such intensity. They conclude that "the chromosomal determination of sex is reinforced very early in foetal life by endocrine influences of foetal origin." Similar fuchsinophil staining was found in the adrenals of pseudohermaphrodites. However other pathologists have not obtained such consistent results in virilism, and there seems little doubt that cases clinically identical with those of Broster and Vines do not always show such ponceau-fuchsin staining reaction.

Some cases of adreno-genital syndrome, even of many years standing, may be due to an adrenal neoplasm-adenoma or carcinoma-rather than to hyperplasia. The writer has drawn attention to the possibility of neoplasm being preceded by hyperplasia. The pituitary gland in cases of adreno-genital syndrome, as distinct from Cushing's syndrome, does not show any particular features, although there is a great lack of autopsy material, since the patients do not die with the disease in the absence of neoplasm. In female pseudohermaphrodites (i.e. those with ovaries, enlarged clitoris and hirsutism) there seems little doubt that the condition is due to a genetically determined hyperplasia and excessive distribution of adrenal androgenic cells, since (I) the condition may be associated with severe adrenal metabolic insufficiency, and (2) the adrenal androgenic cells may overflow to the gonads, replacing their normal structure almost entirely. In the case of the adreno-genital syndrome, it seems not unlikely that there is also a genetically determined excess of the andrenal androgen secreting cells. On the other hand, the apparent onset in some cases in adult life, or waves of intensity in adult life, do raise the probability of a pituitary-adrenocortical stimulus as an important if not a primary factor. Further, there is one group of cases which I have described (Simpson, 1948b; 195 Ib) in which a type of adreno-genital syndrome appears to be secondary to mild or obvious acromegaly, and here one must certainly postulate a primary pituitary stimulus, but I think it justifiable to argue that these should be separated off from the larger group of idiopathic adreno-genital syndrome. The problem of pituitary intervention is more complicated when we consider the adipose type of adreno-genital syndrome, since here we have excessive secretion of adrenal glucocorticoids and sometimes an imperceptible gradation into Cushing's syndrome. We must also note in passing that occasionally Cushing's syndrome and acromegaly are met with in the same person, and in at least one case the demonstration of increased ACTH in the blood has been claimed and its disappearance after removal of a pituitary eosinophil adenoma (Eliel and Pearson, 195 I). It is of interest to note that symptomless goitre is met with in the adrenogenital syndrome, in Cushing's syndrome and in acromegaly.

In some cases of adreno-genital syndrome the causative lesion appears to be in the ovary and this is of three kinds:

(I) where adrenal cortex tissue has been included in the embryological descent of the gonads into the pelvis and this usually takes on an adenomatous formation;

(2) an arrhenoblastoma, which is the name given to a tumour arising from the morphological equivalent of rudimentary testicular tissue in the medullary portion of the ovary;

and

(3) ovaries showing bilateral luteal hyperplasia, since sub-total resection from the ovaries in these cases has resulted in a reversal of the syndrome to normality.

Apart from adrenal rests in the ovary, there is histological and experimental evidence that the ovary may in certain circumstances function in the same biological manner as the adrenal gland; thus Clayton and Prunty (195 I) showed that, after adrenalectomy, the ovaries of the rat could respond to ACTH (as judged by the inhibition of reparative cell mitosis) during certain phases of sexual activity such as the breeding season, or after a luteneising hormone stimulus.

With arrhenoblastoma, the tumour arises from the rete ovarii and may be of mild malignancy. Microscopy may reveal primitive convoluted tubules comparable to the structural development of the normally atrophic left gonad of the hen after removal of the right ovary has led to virilism and sex reversal.

\section{Hormone Studies}

That the adrenals secreted androgens was indicated by cases of virilism and hirsutism in women associated with adrenal tumours, and some in- 
stances have been described of extreme virilism following ovariectomy, so that, apart from ovarian neoplasms, the ovaries had been clinically excluded in such types of case. However, the proof of this by biological assay depended initially on the development of biological methods such as the weight of the prostrate and seminal vesicles in castrated rats, as demonstrated by. Professor Korenchevsky at The Lister Institute over a number of years, and the comb growth of capons as described by Womack and Koch (1932).

While working at The Lister Institute and using Korenchevsky's technique, I was-able to demonstrate, for the first time, an excess of androgenic hormone in a case of adreno-genital syndrome and the results were presented to The Royal Society of Medicine (Simpson, 1934). In the next two years, using the comb growth technique of Paul de Fremery, a series of such cases was investigated and reported in 1936 (Simpson, de Fremery and Macbeth, 1936). The results were as follows: an excess of androgenic hormone was found in 4 out of 7 women with adreno-genital syndrome, 3 women with Cushing's syndrome, and 2 of 3 girls with pseudohermaphroditism. It is of interest that 3 of the women with adreno-genital syndrome did not show any excess of androgenic hormone in the urine, but this can only be intepreted as a failure of the urine to reflect the endogenous secretion of the adrenal gland into the bloodstream.

The work was continued in collaboration with Callow, using the 17 -ketosteroid method of assay which is in common use today, and similar types of results were obtained over a large number of cases. We also inferred from 17-ketosteroid assays in ovariectomized women that the adrenals continued to secrete androgens under these circumstances. These results were presented by Callow to The Royal Society of Medicine in 1938 and are included in a comprehensive review of this field by Parkes (1945). It would also appear that even in virilism, where the androgenic effect predominates, the adrenals, both hyperplastic and neoplastic, may secrete progesterone and oestrogens in normal or excessive quantities, even in the presence of amenorrhoea.

In the male, an adrenal tumour may produce feminisation, and in such cases an enormous excess of oestrogens has been found in the urine (Simpson and Joll, 1938; Burrows, Cook and Warren, 1936).

Insufficient data have been accumulated on the question of urinary glucocorticosteroids in the adreno-genital syndrome, and these are not always demonstrably raised even in Cushing's syndrome, but some investigations indicate raised values in some patients with the adipose type of adreno-genital syndrome (Robinson and Norton, $\frac{}{\alpha}$ 1951). They may also be present in excess in pseudohermaphroditism (Wilkins et al., I95 I).

\section{Hirsutism}

The development of hirsutism with adrenal $\frac{1}{0}$ androgenic tumours and its frequent disappear- $\frac{\bar{\sigma}}{\bar{\sigma}}$ ance with the removal of such tumours, crudely $\underset{\triangle}{\triangle}$ but definitely indicates the effects of an excessive androgenic stimulus. The same is true when testosterone is administered in large doses to women with, for example, carcinoma of the $\overrightarrow{\vec{\omega}}$ breast; and other concomitant results are deepening of the voice, acne and loss of the hair of the 8 head. There appear to be, however, other 3 factors. Thus in some women, in whom an i excessive androgenic stimulus is known to be present, the abnormal hair may be limited to the face and particularly to the chin, the sides of the upper lip and the sides of the face; the body may $\stackrel{\infty}{\oplus}$ continue to be almost free from hair and the vulval 윽 hair remain horizontal as in the majority of normal females: The arms and the legs usually become $\frac{D}{0}$ more hairy than before but this is not necessarily the case. The most probable explanation of such $\overrightarrow{0}$ differences is a genetic distribution of hair follicle they being absent in some women over large areas. of the body. One also meets with men who shor normal body and limb hairiness but have the greatest difficulty in growing any hair on the face, or such hair may be limited to the sides of the chin and the sides of the lip as in the mildly hirsute female. Another important point in considering $\overrightarrow{\overrightarrow{0}}$ the distribution and extent of hirsutism is the 3 intensity of the stimulus and the sensitivity of response of hair follicles in different areas of the body. Thus with a moderate stimulus, unusual $\frac{}{3}$ hair may only be seen between the eyebrows and in the lumbosacral area. An increase in the in- $\frac{5}{3}$ tensity of the androgenic stimulus may lead to nair along the linea alba, over the sternum and round the nipples; also an increase of hair in the vulval and perianal regions. The gluteal regions 9 in the average woman are nearly always hair free, $\frac{D}{0}$ and when these areas become covered with hair and the skin loses its softness and delicacy, an o intense androgenic stimulus can usually be postulated. The thickness of the eyebrows and the length of the eyelashes are also indications of $\mathrm{\omega}$ the calibre of the androgenic stimulus. Gradations of stimuli can also be measured clinically by the thickness and coarseness of the hairs and also by their colour. Thus, with a moderate stimulus ? the hair in unusual places may be fair even in a moderately dark person, but later becomes dark. Pubic hair in the female normally and abnormally $\frac{\rho}{\mathbb{Q}}$ results from an adrenal androgenic stimulus, even 
ADRENALS SECRETE

GLUCORTICOIDS $\downarrow$

(1) Negative nitrogen balance

(2) Osteoporosis

(3) Diabetogenic

(4) Atrophied flabby muscles

(5) Inhibits somatic growth

(6) Skin thin, dry

(7) Appetite +

(8) Increase of weight

(9) Fat anabolism (and (?) catabolism) Protein catabolism

(10) Retention $\mathrm{Na}$ : loss $\mathrm{K}$

(I I) Diminishes hirsutism

(12) Hypertension

(I3) Plethora and polycythaemia

(I4) Depresses thyroid function
ANDROGENS

$\downarrow$

(1) Positive nitrogen balance

(2) Prevents or diminishes osteoporosis

(3) Nil (?)

(4) Strong hypertrophic muscles.

(5) Increases somatic growth in man

(6) Skin thick, greasy, acne

(7) Appetite +

(8) Increase of weight

(9) Fat catabolism Protein anabolism

(10) Retention $\mathrm{Na}$ and $\mathrm{K}$

(I I) Increases hirsutism

(12) Hypertension

(13) Plethora and polycytbaemia

(I4) Increases thyroid function

Fig. 3.-To contrast actions of the two chief types of adrenal hormones. Some are similar but many opposed. This table is not absolute and actions indicated may vary to some extent with circumstances and species.

though this may be released in certain circumstances by ovarian oestrogenic secretion. In the absence of the adrenals, or of the pituitary, oestrogens cannot produce pubic hair. There is of course a considerable variation of hair distribution on the face, body and limbs among normal women; this is genetically and ethnologically determined and the conception of the majority of women being free from hair on the face or limbs has no justification in physiology or fact, as is well known not only to scientists but to the thousands of beauty parlours which endeavour to eliminate any evidence to the contrary. It is equally true that some 15 per cent. of women have a male triangular distribution of abdominal hair or at least hair along the linea alba.

If one investigates the 17 -ketosteroid content of the urine in a large number of women patients, one comes across the fact that some adipose women with high 17 -ketosteroid values show little or no evidence of hirsutism. They are usually adipose and their skin smooth and delicate. It appears probable that the androgenic stimulus is locally inhibited by the simultaneous secretion of a moderate excess of cortisone. This point is brought out even more forcibly in the study of adipose gynandrism and of some adult fat men who might have been examples of adipose gynandrism and who show excess of glucocorticoids in adult life. Thus one adult male recently seen had high normal 17-ketosteroids, namely $18 \mathrm{mg}$. per 24 hours, and glucocorticoids more than twice the normal, i.e. $4.5 \mathrm{mg}$. per 24 hours of the water soluble partition component. This patient had normal genitals and potency, his facial hair had always been thin and soft, and, apart from horizontal pubic hair, his body was completely free from hair and likewise his buttocks, which were covered with soft delicate skin as in the female. The same inhibitory effect of cortisone on hirsutism may manifest itself in Cushing's syndrome.

As to the scalp hair, the first effect of an androgenic stimulus appears to increase the amount of pigment in the hair and to make it coarse and sometimes curly and to produce a greasy seborrhoea. Later there is loss of the hair in the frontotemporal regions and at the vertex, and the patient may become almost bald, as many males normally become with age. In Simmonds's disease, oestrogens increase the lustre and abundance of the hair and may restore pigment where this has been lost (Simpson, 1948a). Thyroid may have similar effects, which are perhaps more marked in the myxoedematous woman, and part of the thyroid effect is probably mediated by the adrenal glands. In one patient with adreno-genital syndrome and hirsutism, the subsequent development of myxoedema resulted in the disappearance of the hirsutism and reduction of the 17 -ketosteroids in the urine.

As to whether idiopathic hirsutism can exist without any other evidence of the adreno-genital syndrome and without the occurrence of an excessive adrenal androgenic stimulus is not always clear. Certainly an andreno-genital syndrome can exist without menstrual or fat abnormalities being prominent and one must admit the possibility of an extensive distribution of hair follicles in abnormal places in some women without necessarily the additional stimulus of excessive androgen secretion. Nevertheless a genetic chronic hyperactivity of the adrenal may be the cause of hirsutism without amenorrhoea and without adiposity, at least 
in the earlier phases. In one such woman of 62 , whom I saw recently, with a gross moustache and beard of ro years' duration but with no hair on the body, hypertension and polycythaemia were present, and her mother had had a similar condition together with diabetes and hypertension. Both had become moderately fat in later life. The men folk of the family were tall and hairy and one was adipose, and diabetes and hypertension were frequently met with in the family history.

\section{Treatment}

The medical treatment of this condition has up to recently been quite djsappointing. Large doses of oestrogens have been advocated both by injection and locally applied. They could theoretically act by direct antagonism to adrenal androgens at the site of action, e.g. hair follicles, or they could inhibit the pituitary gland as in the experimental animal, e.g. rat and mouse. Large doses of oestrogens may produce complete loss of all the granular cells of the pituitary and transformation of the eosinophil and basophil cells into chromophobes with perhaps formation of a large chromophobe neoplasm; and, physiologically speaking, produce the equivalent of a hypophysectomized animalHowever, in actual practice I have rarely seen any worthwhile results from the administration of large doses of oestrogens.

The other procedure that has been well tried out is unilateral adrenalectomy and good results have been claimed in some clinics. Broster in particular has been a pioneer in this field of adrenal surgery and has regarded his results as favourable (Broster, 1939). As far as my clinical observations go (and they are extensive), unilateral adrenalectomy rarely ameliorates hirsutism to an appreciable degree, but occasionally one gets a surprisingly good result which is sufficiently rare to be regarded as anomalous. The procedure does not influence adiposity. It usually, however, has a dramatic effect on amenorrhoea or oligomenorrhoea, producing a regular and more normal menstruation and this may persist for many years. This happens in spite of the fact that hormone assays show that the 17 -ketosteroids, although reduced by the operation, gradually mount within a few months towards their pre-operative value, which must be ascribed to compensatory hypertrophy of the opposite adrenal gland. We must also conclude that the uterus is more sensitive to the diminution of an excessive secretion of androgens than are the hair follicles. I have always taken the view that unilateral adrenalectomy for the adreno-genital syndrome, or for Cushing's syndrome, is comparable to the now obsolete operation of hemithyroidectomy for thyrotoxicosis and that no more can be expected from it than it ̊ actually achieves. A logical extension of the prin- $\overline{3}$ ciple of the operation is to undertake subtotal $\stackrel{\varnothing}{\varrho}$ bilateral adrenalectomy. In the more severe $c$. condition of Cushing's syndrome there is no $\overrightarrow{\vec{F}}$ doubt of its efficacy in the majority of cases in ? which it is undertaken.

\section{Treatment with Cortisone}

The potential therapeutic value of cortisone in $\stackrel{\mathbb{D}}{\varrho}$ the treatment of adrenal androgenic type of hyper- $\$$ function was indicated by Lawson Wilkins (1951, $\overrightarrow{0}$ 1952), who showed that it was effective in reducing the elevated 17 -ketosteroids to normal, and in $\vec{\omega}$ older female pseudohermaphrodites in developing o the breasts to feminine type and in producing $\frac{0}{7}$ normal vaginal smears, enlargement of the labia 3 . and apparently normal menstruation. In one such case the urinary oestroids in a girl of 18 were $\omega_{\omega}$ actually redúced from 80 gamma to 40 gamma during the period of cortisone therapy, suggesting $\vec{\infty}$ to me that excessive androgens dirẹctly inhibit the + effect of oestrogens at the site of action, e.g. $\frac{\text { I }}{I}$ breasts or uterus.

The application of cortisone to adrenal virilism $\frac{7}{0}$ has been studied sporadically and in most cases the period of therapy has been too short to assay ulti- $\overrightarrow{0}$ mate effects. A case under my observation wis recorded as follows:

' The patient was a female of 18 years whoे, at the age of 14 , began to menstruate scantily and at long and irregular intervals, and developed hair on the face and acne on the face $\frac{\mathrm{D}}{\mathrm{Q}}$ and back. She weighed I $12 \mathrm{lb}$. and was $60 \mathrm{in} . \stackrel{\varrho}{\vec{t}}$ in height. On examination she had a narrow $\overrightarrow{\overrightarrow{0}}$ pelvis, small flat breasts with small nipples, and 3 hair on the sides of the face, upper lip and cheeks, on the buttocks, in the anal and vulval regions, and on the arms and legs. Her back윽 was covered with severe and extensive acne. The clitoris was grossly enlarged. She had been 3 treated with ethinyl oestradiol without obvious effect. The 24-hourly urinary values for $17-\frac{0}{3}$ ketosteroids at intervals of about three days before the administration of cortisone were 35 , 국 $32,22,35$ and $23 \mathrm{mg}$; and corresponding $\frac{}{2}$ values during injection of $100 \mathrm{mg}$. of cortisone were $7.6,5.4,6.4$ and $5.3 \mathrm{mg}$. - a clear-cut and $\mathrm{N}$ persistent reduction.

'The patient was unwilling to remain in hospital to permit the study of I7-ketosteroids $\omega$ after leaving off the cortisone. A return to precortisone values after some weeks might be anticipated. There was no obvious effect on the hirsutism during the three weeks of admini- stration, but the patient was delighted with the $\frac{T}{0}$ almost complete disappearance of the general- $\frac{\mathrm{O}}{\mathrm{D}}$ ized acne, which had previously been refractory $\frac{?}{\mathbb{D}}$ 
to all forms of therapy. The effects of longer term therapy will await larger supplies of cortisone for such kind of work. Enlargement of the breasts, more regular menstruation, and some amelioration of the hirsutism would not be improbable.' (Simpson, 1952.)

Bishop et al. (1952) recorded a similar result in a very similar patient; but in a woman of 26 with hirsutism, mild obesity and oligomenorrhoea without enlargement of the clitoris, there was no appreciable lowering of the elevated 17-ketosteroids with $100 \mathrm{mg}$. of cortisone daily. Thorn et al. (I95 I) gave $25 \mathrm{mg}$. of cortisone daily for one month and $12.5 \mathrm{mg}$. daily for two months to a woman of 38 with hirsutism, oligomenorrheoa and obesity since early adolescene and a urinary 17 ketosteroid value of $15 \mathrm{mg}$. per 24 hours. In the first month the 17 -ketosteroids were reduced to ro mg. daily and in the second and third month to $3 \mathrm{mg}$. daily. There was a return of the menses towards a normal pattern but no improvement in hirsutism. Bastenie (1952) has recorded temporary regression of masculinization in three cases and quoted other sporadic observations. $\mathrm{He}$ also recorded that the partition chromatogram showed a pronounced drop, affecting principally the II-hydroxy-I7-ketosteroids, which comprise fractions VI and VII in Dingemanse's fractionation and are regarded as katabolites of the glucocorticoids.
It seems to the writer that although some amelioration of hirsutism might be expected from long-term therapy with cortisone, the method can hardly be regarded as physiological, or devoid of disadvantages, where the patient is also secreting normal or excessive amounts of adrenal glucocorticoids, and in fact in the latter type of case one would probably require massive doses of cortisone to secure an appreciable reduction in the urinary androgens. Cortisone therapy seems appropriate in the muscular type of adreno-genital syndrome with undeveloped or involuted breasts, enlarged clitoris, high 17-ketosteroids and low glucocorticoids.

If an adrenal androgenic tamour (or for that matter an ovarian tumour) is responsible for the syndrome, the removal of such a tumour will in most cases produce a complete cure, but in some the hirsutism still paradoxically persists in some degree. This has been explained by some rather occult power of hair follicles to remain active once stimulated even though the abnormal stimulus has been removed. This may be so, but I take the opposite view that, although the urinary androgens may not be excessive, the endogenous stimulus persists in the remaining hyperplastic adrenal, and this theory may be correlated with my other proposition that hyperplasia may become neoplasia (Simpson, 1953). The problem nevertheless is admittedly complex and worthy of further intense study.

\section{BIBLIOGRAPHY}

BASTENIE, P. (1952), Lancet, ii, 197.

BISHOP, P. M. F., BRAY, B. M., DE MOWBRAY, R. R., MERIVAI.E. W. H. H., and VAUUGHAN-MORGAN, J. (1052), Ibid., i, 1288.

BROSTER, L. R. (1939), Brit. F. Surg., 26, 925.

BROSTER, L. R.: ALLEN, C., VINES, H: W. C., PATTERSON J., GREENWOOD, A. W., MARRIAN, G. F., and BUTLER G. C. (1938), 'The Adrenal Cortex and Intersexuality,' Chapman \& Hall Ltd., London.

BROSTER, L. R., GARDINER HILL, H., and GREENFIELD, J. G. (1932), Brit. Э. Surg., 19, 557.

BUELOCH, W., and SEQUEIRA, J. H. (1905), Trans. Path. Soc. Lond., 56, 189.

BURROWS, H., COOK, J. W., and WARREN, F. L. (1936), $f$. Soc. Chem. Ind., 55, 1031.

CALlOW, R. K. (1938), Proc. $R$. Soc. Med., 31, 841.

CLAYTON, B. E., and PRUNTY, F. T. G. (1951), f. Endocrinol., 7,362 .

ELIEL, L. P., and PEARSON, O. H. (1951), f. Clin. Endocrinol., II, 913 .

GALLAIS, A. (1912), Le Syndrome génito-surrénal, Thése de Paris, No. 225 .

HOLMES, G. (1924), Quart. F. Med., 18, 143.

PARKES, A. S. (1945), Physiol. Rev., 25, 2.
ROBINSON, A. M., and NORTON, J. M. (1951), f. Endocrinol., 7, 321 .

SIMPSON, S. L. (1934), Proc. R. Soc. Med., 27, 2 r.

SIMPSON, S. L. (1948a), Ibid., 41, 192.

SIMPSON, S. L. (1948b), 'Major Endocrine Disorders,' Oxford University Press.

SIMPSON, S. L. (1950), Postgrad. Med. F., 26, 201 and 417.

SIMPSON, S. L. (195 ra), Proc. R. Soc. Med., 44, 453.

SIMPSON, S. L. (1951b), Bull N.Y. Acad. Med., 27, 723.

SIMPSON, S. L. (1952), Lancet, ii, $9 \mathrm{r}$.

SIMPSON, S. L. (1953), Proc. R. Soc. Med., 46, 39

SIMPSON, S. L., DE FREMERY, P., and MACBETH, A. (1936), Endocrinology, 20, 363 .

SIMPSON, S L., and JOLL, C. A. (1938), ${ }^{i}$ Ibid., 22, 595.

THORN, G. W. RENOLD, A. E., WILSON, D. L., FRAWLEY, T. F., JENKINS, D., GARCIA-REYES, J., and FORSHAM, P. H.' (195I), New Engl. F. Med., 245, 549.

WILKINS, L, LEWIS, R. A., KLEIN, R., GARDNER, L. I., CRIGLER. J. F., ROSENBERG, E., and MIGEON, C. J. (I95I), F. cin. Endocrınol., II, I.

WILKINS, L., GARDNER, L. I., CRIGLER, J. F., SILVERMAN, S. H., and MIGEON, C. J. (1952), Ibid., 12, 257.

WOMACK, E. B., and KOCH F. C (1932), Endocrinology, 16, 273. 